REVIEW ARTICLE

\title{
Mentalization in borderline individuals: an attempt to integrate contradictory research results
}

\author{
Monika Jańczak \\ Institute of Psychology, Adam Mickiewicz University in Poznań, Poland
}

Researchers have been striving to explore the functioning of patients with borderline personality disorder from the perspective of their capacity to mentalize. Analyzing the expanding body of literature, it is nevertheless difficult to reach a clear conclusion. There are studies that confirm mentalization deficits in this group; however, there are also reports suggesting better or at last equal mentalizing in borderline individuals compared to controls. This paper discusses a hypothetical explanation of these contradictory results by analyzing three fundamental issues. It is assumed that: (1) different aspects of mentalization are measured in studies - some of them are disordered, while others remain intact in borderline individuals; (2) mentalization can be understood not only as a trait but also as a state, and its level may differ in the same person depending on measurement conditions; (3) the borderline group is heterogeneous in terms of mentalizing because other variables determine the level of this capacity.

\section{KEY WORDS}

borderline personality disorder; mentalization; borderline personality organization

Corresponding author - Monika Jańczak, Ph.D., Institute of Psychology, Adam Mickiewicz University in Poznań,

89 AB Szamarzewskiego Str., 60-568 Poznań, Poland, e-mail: mmarszal@amu.edu.pl

AUthors' CONTRIBUtion - A: Study design - B: Data collection - C: Statistical analysis - D: Data interpretation .

E: Manuscript preparation · F: Literature search · G: Funds collection

TO CITE THIS ARTICLE - Jańczak, M. (2018). Mentalization in borderline individuals: an attempt to integrate contradictory research results. Current Issues in Personality Psychology, 6(4), 266-278.

RECEIVED 08.09.2017 · REVIEWED 08.01.2018 · ACCEPTED 13.09.2018 · PUBLISHED 07.12.2018 


\section{BACKGROUND}

The assumption about a specific deficit in the ability to recognize mental states as a possible pathomechanism associated with borderline personality disorder (BPD) was formulated for the first time by Peter Fonagy in an article demonstrating the links between a childhood traumatic experience and the type of attachment later in life (Fonagy, 1996). Since that time, for 20 years, researchers and clinicians all over the world have been striving to explore and describe the functioning of patients with borderline personality disorder from the perspective of their capacity to mentalize. Analyzing the extremely extensive and constantly expanding body of literature devoted to this area (an increase in the number of records in the EBSCO search engine from below 100 in 2000 to nearly 3,000 now), it is nevertheless difficult to reach a clear conclusion that could be an answer to the following question: does the level of mentalization in borderline individuals differ from the level observed in healthy people and in individuals with other mental disorders? There are studies that confirm the thesis originally formulated by Fonagy and his team concerning mentalization deficits in this group. However, there are also reports to the contrary - suggesting better or at last equal capacity to mentalize in borderline individuals compared to control groups. It was not until very recently that some authors attempted to integrate these contradictory research results, creating more complex models of mentalization disturbances in this group (Dinsdale \& Crespi, 2013; Sharp, 2014).

Studies on mentalization in borderline individuals can be divided into three groups: (1) studies in which disordered mentalization was found in borderline individuals (Baez et al., 2014; Cierpiałkowska, Kwiecień, \& Miśko, 2016; Dziobek et al., 2011; Fischer-Kern et al., 2010; Górska \& Marszał, 2014; Lecours \& Bouchard, 2011; Preißler, Dziobek, Ritter, Heekeren, \& Roepke, 2010; Sharp et al., 2011); (2) studies in which increased mentalization was found in borderline individuals (Arntz, Bernstein, Oorschot, \& Schobre, 2009; Fertuck et al., 2009; Flury, Ickes, \& Schweinle, 2008; Franzen et al., 2011; Harari, Shamay-Tsoory, Ravid, \& Levkovitz, 2010; Scott, Levy, Adams, \& Stevenson, 2011); (3) studies in which no differences in the level of mentalization were found between borderline individuals and controls (Ghiassi, Dimaggio, \& Brüne, 2010; Schilling et al., 2012). According to an interesting meta-analysis presented by Dinsdale and Crespi (2013), out of 40 tasks measuring various aspects of social cognition and empathy in individuals with borderline personality disorder, 13 indicated better functioning of the clinical group compared to the control group, 13 showed worse functioning of people with BPD, and 14 showed the same level of functioning. In the present article I will attempt to explain these contradictory research results. Because a thorough review of most of the cited studies was done in the aforementioned paper (Dinsdale \& Crespi, 2013), let me proceed directly to commenting on the obtained results.

Based on the analysis of the available literature and a number of studies on mentalization conducted at the Department of Health Psychology and Clinical Psychology of the Institute of Psychology, Adam Mickiewicz University (Cierpiałkowska \& Górska, 2016; Marszał, 2015; Bączkowski \& Cierpiałkowska, 2015), it can be hypothesized that it is possible to explain the apparently contradictory results on mentalization in borderline individuals by analyzing three fundamental issues: the way mentalization is operationalized, the conditions in which measurement is performed, and the analyzed samples. It can be assumed that: (1) different aspects of the capacity to mentalize are measured in studies - some of them are disordered, while others remain at a normal level in the case of borderline individuals (different mentalizations); (2) mentalization can be understood not only as a trait but also as a state, and its level may differ in the same person depending on measurement conditions, which means that, in the same person, mentalization may be disordered at one moment and optimal at another (different measurement conditions); (3) the group of borderline individuals is heterogeneous in terms of the capacity to mentalize because other variables determine the level of this capacity (different types of borderline personality). Let me now discuss each of these theses.

\section{DIFFERENT MENTALIZATIONS}

\section{MENTALIZATION AND THEORY OF MIND}

The first reason why studies on mentalization in borderline individuals yield contradictory results is the fact that the term "mentalization" is used with reference to completely different processes/abilities or to different aspects of the same ability. Semerari and colleagues (2015) refer to this idea as the selective impairment hypothesis. A great number of processes make up the complex process of inferring mental states (such as: emotion recognition, decoding and inferring mental states, theory of mind, cognitive and affective empathy, emotional intelligence), and only some of them are disordered in borderline individuals. As we managed to demonstrate elsewhere (Górska \& Marszal, 2014), what seems to be particularly important is the distinction between theory of mind, rooted in the cognitive psychology tradition, and the clinically and psychodynamically based multidimensional and complex mentalization. It seems reasonable to distinguish at least two broad aspects of the understanding of phenomena in terms of men- 
tal states: the emotional-regulatory aspect (mentalization) and the cognitive-perceptual aspect (theory of mind) (Górska \& Cierpiałkowska, 2016). The former is responsible for the "hot" (online) knowledge of mental states. It is developmentally related to secure attachment, emotion regulation, and parent's ability to mentalize (Ensink, Normandin, Plamondon, Berthelot, \& Fonagy, 2016; Meins et al., 2002; Sharp \& Fonagy, 2008; Stawicka \& Górska, 2016). Mentalization and emotion regulation ability develop in the context of secure attachment, mainly thanks to the understanding and elaborating of the child's emotional states by the caregiver in the context of the dyadic regulatory system. Both Polish studies (Cierpiałkowska et al., 2016; Górska \& Marszał, 2014) and international ones (Fischer-Kern et al., 2010; Ha, Sharp, Ensink, Fonagy, \& Cirino, 2013; Müller, Kaufhold, Overbeck, \& Grabhorn, 2006) have revealed a relationship between mentalization understood in this way and borderline pathology. Also very important is the regulatory function of mentalization, confirmed by studies on the relationship between mentalization and emotional dysregulation (Fossati, Borroni, Dziobek, Fonagy, \& Somma, 2017; Sharp et al., 2011; Marszał \& Jańczak, 2017). In this perspective, mentalization is responsible both for appropriate navigation in the social world and for the self-regulation ability; it refers to the same degree to the inference of one's own and other people's mental states - these two processes are closely interrelated.

By contrast, traditionally understood theory of mind refers mainly to cognitive functioning - to conscious inference and perceptual recognition of mental states. This is more "cold" (offline) knowledge of mental states, consisting in the understanding of other people's minds, not one's own. As far as the developmental perspective is concerned, associations are found between theory of mind and the level of the child's linguistic functioning, his or her temperamental traits, executive functions (mainly cognitive flexibility, inhibitory control, and working memory), as well as family structure, socioeconomic status, and parental mind-mindedness (Białecka-Pikul, 2012; Marszał \& Kamza, 2016). Some studies, however, suggest a limited association between theory of mind and attachment (Fossati et al., 2017; Laranjo, Bernier, Meins, \& Carlson, 2014; Meins et al., 2002), and what turns out to be a predictor of the child's theory of mind is the mother's verbal abilities, not her capacity to mentalize or secure attachment (Meins et al., 2002; Ontai \& Thompson, 2008). Serious deficits in this function have been found in many Axis I disorders, such as autism, schizophrenia, depression, brain injuries, or anorexia (Bora \& Pantelis, 2013; Oldershaw, Treasure, Hambrook, Tchanturia, \& Schmidt, 2011; White, Hill, Happé, \& Frith, 2009). Studies on the relationship between theory of mind and emotional disorders are much less conclusive: contradictory results are obtained on anxiety disorders, mood disorders, and obsessive-compulsive disorders (Inoue, Tonooka, Yamada, \& Kanba, 2004; Sayin, Oral, Utku, Baysak, \& Candansayar, 2010), which may attest to a limited association between theory of mind and emotional functioning. As regards patients with BPD, most studies point to a lack of disturbances or even to better functioning (Fertuck et al., 2009; Gooding \& Pflum, 2011; Scott et al., 2011). Correlational studies (Górska \& Marszał, 2014) revealed no relationship between theory of mind measured with the Strange Stories Test (Happé, 1994) and mentalization measured with the Mental States Task (Beaulieu-Pelletier, Bouchard, \& Philippe, 2013), either in the group of healthy people or among patients with borderline personality organization. Support for the distinction between theory of mind and mentalization is also provided by studies on recognizing mental states in individuals with a high level of psychopathic traits. Taubner et al. (2013) demonstrate that individuals from this group score high on tasks connected with "offline" knowledge of mental states, while deficits manifest themselves in situations that are emotionally engaging and concern a complex interpersonal context. It therefore seems that cognitively understood theory of mind is connected with a different developmental context and refers to a different mechanism responsible for recognizing mental states, although it cannot be excluded that it is somehow related to psychodynamically understood mentalization. However, theory of mind is equally available to people with high and low levels of emotional and structural pathology. To sum up, studies on theory of mind and mentalization address different aspects of inference about mental states, hence the contradictory results. At the same time, there is a lack of studies investigating the relations between mentalization as understood in these two research traditions. They would certainly be of great value for explaining these complex relations.

\section{DIFFERENT METHODS OF MEASURING MENTALIZATION}

These questions about the manner of conceptualizing mentalization and the different levels at which mentalization manifests itself naturally entail differences in operationalization and measurement (Marszał, 2016). The tools used in research will differ depending on the approach adopted. The methods of measuring mentalization can be classified according to several criteria: (a) according to complexity level - from simple tests measuring isolated functions to complex batteries aimed at faithfully reproducing the natural conditions of functioning; (b) according to whether they involve mainly cognitive processes, emotional processes, or both at the same time; 
(c) according to the necessity of making inferences about mental states - from tasks concerning only the prediction of other people's behaviors to complex instruments referring also to the subject's own emotions and experiences in the context of relations with others; (d) according to the processes involved from exclusively perceptual tasks to tasks involving many different functions: from perception, through inference, to the regulation of one's own functioning in the social world; (e) methods involving only conscious, controlled processes, and methods involving also the automated and more unconscious ones. It seems obvious that the results will differ depending on what instrument is used. Many authors point out, for instance, that mentalization disturbances in borderline individuals manifest themselves only during complex tasks, engaging many different functions and requiring the integration of complex social stimuli as well as activity at the conscious and unconscious levels (Brüne, Walden, Edel, \& Dimaggio, 2016; Dziobek et al., 2011; Petersen, Brakoulias, \& Langdon, 2016). Research results confirm this, to some extent. The vast majority of studies using the Reading the Mind in the Eyes Test (Baron-Cohen, Wheelwright, Hill, Raste, \& Plumb, 2001), measuring the perceptual aspect of recognizing mental states on the basis of a photograph of the area around the eyes, found better or equal functioning in borderline individuals compared to healthy people (Baez et al., 2014; Fertuck et al., 2009; Preißler et al., 2010; Schilling et al., 2012). This means that borderline individuals exhibit greater sensitivity to stimuli connected with the expression of emotions - which, paradoxically, may cause problems in adequate social functioning. No abnormalities or better functioning of borderline individuals was found also in studies using classical tasks rooted in the cognitive perspective on theory of mind: Strange Stories (Arntz et al., 2009; Górska \& Marszal, 2014) and the Mental State Attribution Task (Ghiassi et al., 2010). Only in the faux pas recognition test do borderline individuals function worse than controls (Baez et al., 2014; Harari et al., 2010; Petersen et al., 2016); this may be a sign of difficulties in the integration of cognitive and emotional inference about other people's mental states, which this task appears to be particularly sensitive to. The results of studies using more complex methods, reproducing the natural context - studies using the battery called the Movie for the Assessment of Social Cognition (MASC; Dziobek et al., 2006, 2011; Fossati et al., 2017; Preißler et al., 2010; Ritter et al., 2011) as well as methods of coding interviews, rooted in the psychodynamic tradition (Fischer-Kern et al., 2010; Marszał, 2015) - almost unambiguously indicate a mentalization deficit in borderline individuals. The latter also refers especially to that aspect of mentalization which is connected with understanding one's own mental states and with using that knowl- edge not only to navigate adequately in the social world but also to regulate relational and emotional functioning in a broader sense. In sum, results show the absence of deficits in the case of less complex studies based on cognitive theory of mind and severe deficits in studies using instruments rooted in the psychodynamic tradition. Interestingly, the latest study by Fossati et al. (2017) revealed a positive correlation (from .40 do .60) between the Reading the Mind in the Eyes Test scores and the level of mentalization measured with the MASC in individuals without personality disorders, in a sample of adolescents and adults. This is a very interesting result, pointing to a possible different mechanism behind mentalization processes in healthy people compared to borderline individuals. No such comparison has been performed so far in this group of people, but the available research results show that BPD patients do well in the Reading the Mind in the Eyes Test and poorly in the MASC - the pattern of correlations would probably be different than in the case of healthy subjects.

The last issue connected with "different mentalizations" is the multifaceted and multidimensional nature of the function responsible for the understanding of mental states. Even if we reflect on the way mentalization is conceptualized and choose one of the two research traditions, the measured construct will still not be homogeneous and, consequently, in the borderline pathology some of its components may be lowered and others heightened or the same as in healthy people. Sharp and Kalpakci (2015) recommend that mentalization should be approached in the same way as the issue of intelligence (IQ) is approached in psychology - as a function in which specific factors contribute to and determine the overall level of functioning. And thus, according to an Italian team exploring metacognition issues, mentalization is constituted by three main functions (recognizing one's own and other people's mental states and using the knowledge about them for behavior regulation) and 10 subfunctions (e.g., monitoring, differentiation, integration, decentration); their levels may vary depending on the type of disorder (Carcione, Dimaggio, Conti, Fiore, \& Semerari, 2010). Although scholars in Fonagy's team usually operationalize mentalization as an individual indicator within the Reflective Functioning Scale (RFS; Fonagy, Target, Steele, \& Steele, 2002), they extensively describe four dimensions of mentalization, also attempting to demonstrate the specificity of the configuration of these dimensions depending on the type of personality disorder (Fonagy \& Luyten, 2009). Diversity also concerns various aspects of theory of mind - as studies show, its aspects include those that may be better (perception and decoding mental states on the basis of a visual stimulus), the same (inference about the causes of behaviors and recognizing simple social situations), or worse (complex recognition, understanding, and pre- 
diction of other people's behavior, requiring the integration of many different stimuli) in borderline individuals compared to healthy ones. The complexity and heterogeneity of the construct of mentalization itself is, therefore, undoubtedly one of the factors responsible for the ambiguous results obtained in studies on social cognition in borderline individuals.

\section{DIFFERENT MEASUREMENT CONDITIONS - SITUATIONAL FLUCTUATION OF MENTALIZATION}

The next issue that may, to some extent, explain the contradictory reports on mentalization in borderline individuals is the two approaches to the understanding and study of mentalization: (1) as a stable personality trait - with the assumption that the level of mentalization is every participant's trait and remains the same regardless of measurement conditions, or (2) as a changeable state, a characteristic whose level may change depending on the specific situation (also on measurement conditions) (Górska \& Cierpiałkowska, 2016; Luyten \& Fonagy, 2015; Marszał, 2015). Taking this situational changeability into account (or not) may lead to contradictory results on mentalization level in borderline individuals. Theoretical considerations and a growing number of empirical studies reveal that the level of mentalization may change depending on the level of emotional arousal, attachment system activation or deactivation, and the type of relationship it concerns. In some sense, these three variables refer to different perspectives on the same phenomenon - namely, in the context of a relationship with a significant other in response to a certain stimulus (actual, such as a threat of being abandoned by the partner, or imaginary, such as the evoked sense of rejection in the relationship with a friend) the attachment system may be activated, which is experienced at the level of neurophysiological processes as high emotional arousal. According to Fonagy and his colleagues, what happens in borderline individuals in such conditions is a breakdown of the capacity to mentalize, a transition from the controlled mode to a more automatic mode and to mentalizing in prementalization modes, developmentally earlier than mentalizing: pretend mode, psychic equivalence mode, and teleological mode (Bateman \& Fonagy, 2010). The process thus described seems to be consistent with clinical experience, especially with observations concerning the functioning of borderline individuals in psychotherapy; these are often patients who are generally capable of navigating well in the social world; considerable problems in interpersonal functioning appear only in the context of close relationships: with the partner, with the family, or with the therapist. It turns out, however, that the effects of attempts at the empirical verification of this pathomechanism are not entirely unambiguousIn experimental research reported elsewhere (Marszał, 2015), the level of mentalizing in individuals with borderline personality organization was compared between two conditions: in emotional arousal connected with the activation of internal working models of attachment, and in a neutral context - that is, in a situation of no emotional arousal and attachment system deactivation. The procedure of attachment system activation consisted in evoking and describing the thoughts and feelings accompanying an imaginary situation connected with frustrating (insecure attachment activation) or satisfying (secure attachment activation) behavior of an attachment figure. Mentalization level was measured with the above-mentioned method of interview coding - the Metacognition Assessment Scale (Carcione et al., 2010). It turned out that the group of borderline individuals was diverse in terms of changes in access to mentalizing caused by attachment system activation; in some subjects a total breakdown of the capacity to mentalize occurred, affecting all dimensions of mentalization (the understanding of one's own and other people's mental states as well as regulating one's own behavior based on knowledge about mental states); in a different group, a breakdown of mentalization occurred only in the dimension of understanding one's own mental states; finally, in the last of the groups distinguished there was an increase in the level of mentalization in all of its dimensions. With regard to the last result, a question arises of whether this is indeed adequate mentalizing or rather hypermentalizing - excessive and projection-based focus on recognizing mental states (Górska \& Cierpiałkowska, 2016). Unfortunately, the instrument used in the study does not make it possible to exclude this possibility altogether. Importantly, the weakening or improvement of mentalizing was not related to the type of activation secure or insecure attachment - or to the initial level of mentalization in the neutral condition. This means that a high level of mentalization in a neutral context is not a significant determinant of maintaining a particular level of this capacity in the context of a close relationship. The obtained results generate more questions than answers and inspire a search for other variables, not included in this model, that may be significant for mentalizing in borderline individuals in the developmental context and subsequently manifest themselves at the level of representations, resulting in different consequences in adult life. A particularly interesting issue seems to be the mechanisms responsible for the formation of pathological personality structure in which access to certain functions (including mentalization) is retained or even improves despite the activation of internal structures connected with insecure attachment. I shall return to this in the final section of this article. 
It is worth noting that a different study (Cierpiałkowska et al., 2016), with a different research procedure, yielded more unambiguous results, showing the worse functioning of borderline individuals compared to controls in terms of mentalization in the context of an activated attachment system. These results are consistent with those of the already cited studies involving interviews in which borderline individuals unambiguously exhibited mentalization deficits. There have also been studies on change in the level of mentalization caused by attachment system activation, conducted on individuals without pathological personality structure (Górska, 2015). The subjects scored higher on mentalization than borderline individuals, although also in this group of people a diverse level of this capacity was found, as well as specific fluctuations in access to mentalization following the activation of various attachment representations. These results are confirmed in the study by Fossati (Fossati et al., 2017), who found not only fluctuations in the capacity to mentalize in healthy people but also a limited relationship between insecure attachment and low mentalization.

The issue of measurement conditions, presented here, is evidently linked with the issue of conceptualization and operationalization of mentalization, described in the previous section of this paper. This idea was taken up by Sharp (2014), who suggested a possible explanation of the contradictory research results by taking into account the level of emotional arousal connected with the aforementioned transition between controlled and automatic mentalizing, as well as with the level of complexity of the tasks measuring mentalization and their similarity to the natural context. As indicated by Dindsdale and Crespi (2013), a high level of stress and emotional arousal, causing a transition from controlled, effort-based mentalizing to a more unconscious, automatic mode, is very unlikely to occur in the case of performing contextually neutral tasks, which manifests itself in the absence of deficits in mentalization measured in this way. Theory of mind is understood as an unchanging personality trait - a particular person is characterized by a certain level of the capacity to infer other people's mental states regardless of the activation of his or her own representations concerning a given relationship or the individual whose mental states he or she infers. In the psychodynamic approach, much greater emphasis is placed on analyzing mentalization in the context of a relationship with an attachment figure, which means that, implicitly, the level of this capacity is described in the context of a close relationship and emotional arousal. This is reflected in the instruments used: in this latter approach, the most established method involves systems of coding interviews about important and emotionally engaging relationships, whereas what dominate in studies on theory of mind are contextually neutral tasks concerning the recognition of mental states of fictional characters of stories or people presented in photos or drawings. It can be assumed that giving an interview about close relationships is itself an element activating the attachment system, which means that measurement in the context of an interview - as opposed to measurement by means of test or experimental instruments - relates to the level of mentalization in a condition of stimulation of inner representations of relations. It seems that, in the case of complex experimental instruments such as the MASC battery, which consists in recognizing the mental states of film characters, in response to stimuli similar to the natural context, the subject unconsciously activates his or her own representations concerning emotions and relationships; the subject becomes emotionally engaged in the performance of the task, which is reflected in a pattern of results close to that obtained by using interviews. By contrast, measurement involving social stimuli abstracted from the context does not lead to activation of the attachment system, which is reflected in maintenance of the optimal level of mentalization in the group of borderline individuals.

To sum up, although there still is a shortage of studies exploring the differences in mentalizing found in borderline individuals (as well as healthy people and subjects from other clinical groups) in various conditions involving the activation of attachment representations, it can be stated that the level of mentalization in the same person differs depending on measurement conditions (attachment system activation vs. deactivation). Consequently, the results of studies are contradictory because they measure mentalization in the conditions of both activation and deactivation of the attachment system without acknowledging this distinction.

\section{DIFFERENT TYPES OF BORDERLINE PERSONALITY}

Many authors, referring to a variety of circumstances, point out that borderline individuals are a highly diverse group. Even definitional issues themselves pose certain difficulties. Borderline pathology can be understood as a nosological diagnosis in accordance with international psychiatric classifications (ICD-10, DSM-5), or as a diagnosis concerning the level of personality structure in accordance with the psychodynamic approach (Cierpiałkowska \& Gościniak, 2010; Kernberg, 2004). These approaches have different implications for reflection on the level of mentalization and involve different problems stemming from the heterogeneity of the group labeled as borderline. For instance, in the psychiatric approach there are 256 combinations of the symptoms listed in DSM-5, based on which BPD is diagnosed (Levy, Scala, Temes, \& Clouthier, 2015). However, above all, apart from 
obvious differences in symptomatology, borderline individuals differ among themselves both in terms of intrapsychic mechanisms and structures (e.g., attachment representation, defense mechanisms, emotion regulation strategies, or the degree of identity integration) and in terms of the background of the disorder (experience of early childhood trauma, corrective experiences in later life, type of temperament). So far, relatively few studies have been devoted to testing the hypothesis postulating a complex pathogenesis of mentalization disorders as well as to testing the relations between the level of mentalization and variables such as the type of defenses used or the presence of early childhood trauma experience. It seems probable that differences in these aspects may diversify the group of borderline individuals in terms of mentalization level and that significant differences in this respect can be expected.

\section{MENTALIZING IN BORDERLINE PERSONALITY ORGANIZATION}

To some extent, the results of studies reported in the literature confirm the legitimacy of analyzing mentalization level in the context of the entire disordered personality structure rather than only a certain group of symptoms characteristic of BPD. This is attested by results revealing mentalization disturbances also in other personality disorders, classified by Kernberg as characterized by pathological personality structure (borderline personality organization) and by a number of studies comparing individuals with borderline personality organization and those without a structural pathology (Cierpiałkowska et al., 2016; Fossati, Feeney, Maffei, \& Borroni, 2014). The study that could be regarded as pioneering in this field is the one by Fisher-Kern et al. (2010), who found a relationship between mentalization measured with the RFS and the level of personality organization the higher the mentalization, the lower the likelihood of pathological personality structure.

In the literature there is a lack of comparative studies concerning differences in mentalization between individuals with different personality disorders as defined in psychiatric classifications. Studies on small samples have provided information about specific mentalization disturbances in various personality disorders other than BPD (Dimaggio et al., 2007, 2009; Semerari et al., 2005), most of them classified by Kernberg as borderline personality organization. The most recent comparative study (Semerari et al., 2015) revealed that BPD patients exhibited a characteristic configuration of mentalization disturbances compared to subjects with other personality disorders. They scored significantly lower on two mentalization scales: Differentiation and Integration. Disturbances in this area, together with a high overall level of psy- chopathology, allowed a given person to be classified in the borderline group to the greatest degree. In studies using the RFS, the investigators found a low level of mentalization in subjects with BPD and in individuals with comorbid BPD and narcissistic personality disorder; subjects from these groups did not differ in terms of mentalization (Diamond et al., 2014). Comparative studies using the MASC battery revealed a relationship between mentalization disturbances and the following personality disorders measured by self-report methods: borderline, paranoid, schizotypal, antisocial, dependent, and passive-aggressive. However, an association between mentalization and psychiatric diagnosis was found only in the case of BPD. Many studies have also revealed specific deficits of mentalizing in patients with antisocial personality disorder or psychopathic traits (James \& Blair, 2007; Ritter et al., 2011; Dolan \& Fullam, 2004; Richell et al., 2003). The cited studies show that mentalization disturbances concern not only BPD but an entire spectrum of disorders falling into the category of pathological personality organization, and perhaps it is the severity of pathology understood in this way that is associated with a decrease in the capacity to mentalize - to a greater extent than borderline symptoms at the descriptive level. However, those few and inconclusive studies conducted among individuals with other personality disorders also suggest a certain specificity of mentalization deficits depending on the type of personality disorder as understood in nosological diagnosis/phenomenology. This corresponds to the new perspective on personality disorders in DSM-5 (American Psychiatric Association, 2013), stressing the need to determine the overall severity of the disorder on the one hand and the distinctive symptoms (personality style) on the other. The study by Semerari et al. (2014) confirms the significance of this distinction for mentalization-related functioning: the authors found that mentalization disturbances were stronger in the group of subjects with personality disorder compared to the control group (without personality disorders, but with Axis I disorders), and that their level was associated with overall disorder severity (the higher the number of personality disorder symptoms, the lower the level of mentalization); however, the authors also found associations between specific mentalization disturbances and personality styles. It seems that the issue of mentalization in borderline individuals can be analyzed on two levels: as a problem of a particular mentalization-based pathomechanism being specific to this disorder (in comparison with other disorders, mainly personality disorders - in this case the control group consists of individuals with other mental disorders) and as an attempt to describe pathological mentalization processes as opposed to their optimal course (in this case, the control group consists of healthy individuals). These are two different research problems, which imply different consequences for 
the study of mentalization. To sum up, it seems to be important when describing the level of mentalization to refer both to the level of pathology (personality structure disorders, differentiation "in depth") and to the type of symptoms (personality style, differentiation "in breadth", according to descriptive diagnosis).

\section{MENTALIZATION AND ATTACHMENT STYLE IN BORDERLINE INDIVIDUALS}

Apart from the associations between mentalization and various types of personality disorders, a relatively large amount of attention is devoted to the diversity of borderline individuals in terms of attachment style. This issue seems to be very important, since studies suggest a nonhomogeneous character of the group of borderline individuals in this respect; given the postulated associations between mentalization and attachment both in the developmental context and in the context of intrapsychic mechanisms sustaining borderline disorder, this may be of considerable importance to mentalization level in this group. Although borderline patients usually exhibit an anxious attachment style, some of them are also characterized by a disorganized, avoidant, or even secure style (Fonagy, Luyten, \& Strathearn, 2011; Fossati et al., 2014; Levy \& Blatt, 1999; Levy, Meehan, Weber, Reynoso, \& Clarkin, 2005; Shorey \& Snyder, 2006). Studies also show that what may be of greater significance for mentalization is the specific attachment style (different for each attachment figure; Bączkowski \& Cierpiałkowska, 2015; Marszał, 2014, 2015). These issues seem to be related to the distinct pathogenesis and pathomechanism of borderline disorder, resulting in borderline individuals' different functioning in terms of mentalization. Perhaps, as a result of a different path of disorder development (e.g., depending on temperamental traits or on the experience with caregivers), "different" borderline disorders develop - for instance: borderline with a capacity to build secure attachment (with less disordered or even retained capacity to mentalize), borderline with a predominance of anxious attachment (characterized by a sudden breakdown of mentalizing in the face of a high level of stress and emotional arousal), borderline with a predominance of avoidant attachment (marked by higher resistance to stress and lower frequency of attachment system activation, but also by mentalization disturbances at a sufficiently high level of arousal), and borderline with disorganized attachment (characterized by an indefinite and chaotic pattern of relations between mentalization and attachment system activation or a complete deficit in the capacity to mentalize). Of course, it should be assumed that not only the type of attachment determines the functioning of mentalization and that also many other variables (intra- psychic and interpersonal) have a direct or indirect influence on the presented model of relations. So far, only one study that addressed the relationship between a particular type of mentalization disturbance (measured with the MASC) and attachment style (Fossati et al., 2017) in healthy people has been reported. Associations were found between avoidant style and undermentalizing as well as no mentalizing, between dismissing style and hypermentalizing, between fearful and preoccupied styles and undermentalizing, between anxious/ambivalent style and no mentalizing, and between secure style and good mentalizing (although it should be noted that, generally, the strength of the associations was low, ranging from .15 to .23). This means that people without personality disorders exhibit a low but fairly unambiguous association between mentalizing and attachment - mentalization disturbances are associated with each of the insecure attachment styles, and the more insecure the attachment is, the lower is the level of mentalization. Perhaps in borderline individuals these relationships are more complex, and perhaps, for example, in some situations, a certain level of insecure attachment may be conducive to better mentalization.

Few studies, though very important ones, support the hypothesized nature of the relationships between borderline pathology, the capacity to mentalize, and attachment style. Beeney et al. (2015) compared patients with borderline, avoidant, and antisocial personality disorders in terms of mentalization level and attachment style. Mentalization mediated the relationship between anxious attachment and symptoms of BPD and antisocial personality disorder, but not avoidant personality disorder. It is therefore anxiety, not avoidance, that seems to be of greater significance for mentalization disturbances in the pathomechanism of personality disorders. Based on research on the functioning of individuals with avoidant attachment under the influence of emotional arousal (Mikulincer \& Shaver, 2003), it is possible to infer that these relationships have different mechanisms - perhaps up to a certain moment avoidance in attachment does not affect mentalization. The lack of relationship between mentalization and symptoms of avoidant personality disorder supports the hypothesis that mentalization disturbances occur only in severe personality structure pathology: namely, in the disorders described by Kernberg as borderline personality organization. In the study by Ghiassi et al. (2016), it was also only anxious attachment, not avoidant attachment, that exhibited a relationship with borderline personality characteristics in the group of patients with this personality disorder. The study by Cierpiałkowska et al. (2016) revealed that both the activation of anxiousambivalent and avoidant attachment mediated the relationship between the capacity to mentalize and the borderline personality organization, although most results suggested stronger direct associations 
between mentalization and borderline. In the already cited study by Marszał (2015), a high level of avoidant attachment to father, a low level of avoidance with regard to a friend, and a low level of avoidance with regard to the attachment figure that the person mentalizes "about" were conducive to better mentalization.

The studies outlined here suggest great complexity of the attachment system in borderline individuals, which may be a significant cause of the differences in mentalizing observed in this group. In a very interesting article on attachment in personality disorders, Levy (Levy et al., 2015) describes the way in which different attachment mechanisms may lead to different phenomenological manifestations of borderline pathology. According to the authors, the complex structure of the attachment system, composed of elements of avoidant, anxious, and secure attachment, is associated with different levels of personality development (including the level of differentiation and integration of the internal representations of attachment), which in turn manifests itself in the type of personality disorders. The authors describe BPD as a disorder that may manifest itself both in the avoidant type and in the anxious type (Levy \& Blatt, 1999), which results in different functioning of individuals from these groups, probably also in the area of mentalization.

\section{DIFFERENT FACES \\ OF MENTALIZATION DISORDERS: HYPERMENTALIZING AND HYPOMENTALIZING}

A different issue, no less important, seems to be the explanation of how it is possible that, in some studies, in conditions of attachment system activation, the level of mentalization increases in some borderline individuals (Marszał, 2015). Given that most mental disorders involve decreased social cognition abilities and that a characteristic feature of the functioning of borderline individuals is serious difficulties in interpersonal functioning, what cause the greatest interpretative difficulties are the results indicating the better functioning of borderline individuals as regards the capacity to mentalize. However, from the developmental point of view, this state of affairs seems explicable. In the pathogenesis of BPD, particular importance is attributed to the interaction between the child's unbalanced temperament and the specific answer of the caregiver, who is often experienced as frustrating, self-absorbed, as well as chaotic and irregular as regards the care provided. In special cases, the caregiver is also a direct source of threat or an insufficient source of the sense of security in the face of threat from another person or situation. In such conditions, the young child's adaptive strategy may rely on increased sensitivity and motivation to recognize the caregiver's mental state so as to be able to predict the possible threat as well as to learn to recognize his or her frequently ambiguous, chaotic, and rapidly changing mental states. On the other hand, an equally effective strategy can consist in defensively blocking mentalization processes in order to avoid recognizing the caregiver as a source of danger or as someone who may have bad intentions towards the child. Perhaps these two different mechanisms are responsible for the different patterns of mentalization disturbances later in life: hypermentalizing on the one hand, and weakened or totally "turned off" mentalization in the context of a close relationship on the other. It remains an open question whether or not in studies not directly addressing the issue of increased motivation to mentalize researchers always succeed in distinguishing hypermentalization from normal mentalization. Nevertheless, it can be hypothesized that there are paths connected with both better and worse functioning as regards mentalization - both of them may lead to considerable difficulties in interpersonal functioning connected with borderline pathology (Dinsdale \& Crespi, 2013; Fossati et al., 2017; Sharp et al., 2011). Also the mechanism connected with the process of hypermentalization undoubtedly requires more thorough exploration and comparisons, which would make it possible to determine how it actually differs from optimal mentalizing and how to measure it appropriately in studies.

This brief review of the available literature certainly does not exhaust the subject of the diversity of borderline pathology in terms of pathogenesis and pathomechanism. There certainly is a need to design research projects concerning different paths of development of BPD and their relationships with different types of intrapsychic organization and, consequently, probably also with different functioning in the area of mentalization (see the heterogeneous disorder hypothesis; Semerari et al., 2015). Perhaps this is a good direction to follow in order to explore and describe the different types of mentalization mentioned above - for example those connected with an excessive, constant desire to immediately "guess" other people's thoughts (hypermentalization) or with serious deficits, consisting in a lack of motivation and capacity to recognize and understand mental states (hypomentalization). This is certainly the least explored area so far, which at the same time seems to be the most promising one when it comes to attempts to describe complex phenomena responsible for the process of mentalizing.

\section{CONCLUSIONS}

In this paper, I have tried to indicate various issues connected with the complexity of what is called mentalization in borderline individuals. Analyzing the 
literature on this subject, one may have an impression of chaos: when describing mentalization, authors draw on different theoretical approaches and very different operationalizations, often without addressing the heterogeneity of the borderline group in terms of the origin and mechanism of the disorder. This is the reason why seemingly contradictory results are obtained regarding the level of mentalization in these individuals, who emerge in different studies as better, worse, or similar mentalizers compared to controls. In the present article, I have discussed arguments in favor of three theses that, to some extent, explain the differences observed across studies. Naturally, it should be acknowledged that not all contradictory results can be explained based on these three issues, and that this mode of explanation has certain limitations - as does any attempt at simplifying and categorizing highly complex and dynamic phenomena. Still, it may become a starting point or an inspiration for further research in this immensely interesting area.

\section{RefERENCES}

American Psychiatric Association (2013). Diagnostic and statistical manual of mental disorders: DSM-5. Washington, DC: APA Publishing.

Arntz, A., Bernstein, D., Oorschot, M., \& Schobre, P. (2009). Theory of mind in borderline and cluster-C personality disorder. The Journal of Nervous and Mental Disease, 197, 801-807.

Baez, S., Marengo, J., Perez, A., Huepe, D., Font, F. G., Rial, V., Gonzalez-Gadea, M. L., Manes F., \& Ibanez, A. (2014). Theory of mind and its relationship with executive functions and emotion recognition in borderline personality disorder. Journal of Neuropsychology, 9, 203-218.

Baron-Cohen, S., Wheelwright, S., Hill, J., Raste, Y., \& Plumb, I. (2001). The "Reading the Mind in the Eyes" Test revised version: a study with normal adults, and adults with Asperger syndrome or high-functioning autism. Journal of Child Psychology and Psychiatry, and Allied Disciplines, 42, 241-251.

Bateman, A., \& Fonagy, P. (2010). Mentalization based treatment for borderline personality disorder. World Psychiatry, 9, 11-15.

Bączkowski, B. M., \& Cierpiałkowska, L. (2015). Mentalization within close relationships: The role of specific attachment style. Polish Psychological Bulletin, 46, 285-299.

Beaulieu-Pelletier, G., Bouchard, M.-A., \& Philippe, F. L. (2013). Mental States Task (MST): development, validation, and correlates of a self-report measure of mentalization. Journal of Clinical Psychology, 69, 671-695.

Beeney, J. E., Stepp, S. D., Hallquist, M. N., Scott, L. N., Wright, A. G. C., Ellison, W. D., Nolf K. A., \& Pil- konis, P. A. (2015). Attachment and social cognition in borderline personality disorder: Specificity in relation to antisocial and avoidant personality disorders. Personality Disorders: Theory, Research, and Treatment, 6, 207-215.

Białecka-Pikul, M. (2012). Narodziny i rozwój refleksji nad myśleniem [The Birth and Development of Reflection on Thinking]. Kraków: Wydawnictwo Uniwersytetu Jagiellońskiego.

Bora, E., \& Pantelis, C. (2013). Theory of mind impairments in first-episode psychosis, individuals at ultra-high risk for psychosis and in first-degree relatives of schizophrenia: systematic review and meta-analysis. Schizophrenia Research, 144, 31-36.

Brüne, M., Walden, S., Edel, M.-A., \& Dimaggio, G. (2016). Mentalization of complex emotions in borderline personality disorder: The impact of parenting and exposure to trauma on the performance in a novel cartoon-based task. Comprehensive Psychiatry, 64, 29-37.

Carcione, A., Dimaggio, G., Conti, L., Fiore, D., \& Semerari, A. (2010). Metacognition Assessment Scale v. 4.0. Unpublished manuscript.

Cierpiałkowska, L., \& Gościniak, J. (2010). Wspótczesna psychoanaliza. Modele konfliktu i deficytu [Contemporary psychoanalysis. Models of conflict and deficit]. Poznań: Wydawnictwo Naukowe UAM.

Cierpiałkowska, L., \& Górska, D. (Eds.). (2016). Mentalizacja z perspektywy rozwojowej i klinicznej [Mentalization from the developmental and clinical perspective]. Poznań: Wydawnictwo Naukowe UAM.

Cierpiałkowska, L., Kwiecień, A., \& Miśko, N. (2016). Zdolność do mentalizacji w kontekście relacji przywiązania u osób z zaburzeniami borderline [The ability to mentalize in the context of attachment relation in individuals with borderline disorders]. In L. Cierpiałkowska \& D. Górska (Eds.), Mentalizacja z perspektywy rozwojowej i klinicznej [Mentalization from the developmental and clinical perspective] (pp. 182-207). Poznań: Wydawnictwo Naukowe UAM.

Diamond, D., Levy, K. N., Clarkin, J. F., Fischer-Kern, M., Cain, N. M., Doering, S., Hörz S., \& Buchheim, A. (2014). Attachment and mentalization in female patients with comorbid narcissistic and borderline personality disorder. Personality Disorders: Theory, Research, and Treatment, 5, 428-433.

Dimaggio, G., Carcione, A., Nicolò, G., Conti, L., Fiore, D., Pedone, R., Popolo R., Procacci M., \& Semerari, A. (2009). Impaired decentration in personality disorder: a series of single cases analysed with the Metacognition Assessment Scale. Clinical Psychology \& Psychotherapy, 16, 450-462.

Dimaggio, G., Procacci, M., Nicolò, G., Popolo, R., Semerari, A., Carcione, A., \& Lysaker, P. H. (2007). Poor metacognition in Narcissistic and Avoidant 
Personality Disorders: four psychotherapy patients analysed using the Metacognition Assessment Scale. Clinical Psychology \& Psychotherapy, 14, 386-401.

Dinsdale, N., \& Crespi, B. J. (2013). The borderline empathy paradox: evidence and conceptual models for empathic enhancements in borderline personality disorder. Journal of Personality Disorders, 27, 172-195.

Dolan, M., \& Fullam, R. (2004). Theory of mind and mentalizing ability in antisocial personality disorders with and without psychopathy. Psychological Medicine, 34, 1093-1102.

Dziobek, I., Fleck, S., Kalbe, E., Rogers, K., Hassenstab, J., Brand, M., Kessler, J., Woike, J. K., Wolf, O. T., \& Convit, A. (2006). Introducing MASC: a movie for the assessment of social cognition. Journal of Autism and Developmental Disorders, 36, 623-636.

Dziobek, I., Preissler, S., Grozdanovic, Z., Heuser, I., Heekeren, H. R., \& Roepke, S. (2011). Neuronal correlates of altered empathy and social cognition in borderline personality disorder. Neurolmage, 57, 539-548.

Ensink, K., Normandin, L., Plamondon, A., Berthelot, N., \& Fonagy, P. (2016). Intergenerational pathways from reflective functioning to infant attachment through parenting. Canadian Journal of Behavioural Science, 48, 9-18.

Fertuck, E. A., Jekal, A., Song, I., Wyman, B., Morris, M. C., Wilson, S. T., Brodsky, B. S., Stanley, B. (2009). Enhanced "Reading the Mind in the Eyes" in borderline personality disorder compared to healthy controls. Psychological Medicine, 39, 1979-1988.

Fischer-Kern, M., Buchheim, A., Hörz, S., Schuster, P., Doering, S., Kapusta, N. D., Taubner, S., Tmej, A., Rentrop, M., Buchheim P., \& Fonagy, P. (2010). The relationship between personality organization, reflective functioning, and psychiatric classification in borderline personality disorder. Psychoanalytic Psychology, 27, 395-409.

Flury, J. M., Ickes, W., \& Schweinle, W. (2008). The borderline empathy effect: Do high BPD individuals have greater empathic ability? Or are they just more difficult to "read"? Journal of Research in Personality, 42, 312-332.

Fonagy, P. (1996). Attachment, the development of the self, and its pathology in personality disorders. Psychomedia. Retrieved from http://www.psychomedia.it/pm/modther/probpsiter/fonagy-2.htm

Fonagy, P., \& Luyten, P. (2009). A developmental, mentalization-based approach to the understanding and treatment of borderline personality disorder. Development and Psychopathology, 21, 1355-1381.

Fonagy, P., Luyten, P., \& Strathearn, L. (2011). Borderline personality disorder, mentalization, and the neurobiology of attachment. Infant Mental Health Journal, 32, 47-69.
Fonagy, P., Target, M., Steele, M., \& Steele, H. (2002). Manual for Coding Reflective Functioning. Version 5. University College London Dept of Psychology. Retrieved from http://discovery.ucl.ac.uk/178984/

Fossati, A., Borroni, S., Dziobek, I., Fonagy, P., \& Somma, A. (2017). Thinking About Assessment: Further Evidence of the Validity of the Movie for the Assessment of Social Cognition as a Measure of Mentalistic Abilities. Psychoanalytic Psychology, 35, 127-141.

Fossati, A., Feeney, J., Maffei, C., \& Borroni, S. (2014). Thinking about feelings: Affective state mentalization, attachment styles, and borderline personality disorder features among Italian nonclinical adolescents. Psychoanalytic Psychology, 31, 41-67.

Franzen, N., Hagenhoff, M., Baer, N., Schmidt, A., Mier, D., Sammer, G., Gallhofer, B., Kirsch, P., \& Lis, S. (2011). Superior "theory of mind" in borderline personality disorder: An analysis of interaction behavior in a virtual trust game. Psychiatry Research, 187, 224-233.

Ghiasi, H., Mohammadi, A., \& Zarrinfar, P. (2016). An Investigation into the Roles of Theory of Mind, Emotion Regulation, and Attachment Styles in Predicting the Traits of Borderline Personality Disorder. Iranian Journal of Psychiatry, 11, 206.

Ghiassi, V., Dimaggio, G., \& Brüne, M. (2010). Dysfunctions in understanding other minds in borderline personality disorder: a study using cartoon picture stories. Psychotherapy Research: Journal of the Society for Psychotherapy Research, 20, 657-667.

Gooding, D. C., \& Pflum, M. J. (2011). Theory of Mind and psychometric schizotypy. Psychiatry Research, 188, 217-223.

Górska, D. (2015). Mentalization, specific attachment, and relational satisfaction from the intrapsychic and interpersonal perspectives. Polish Psychological Bulletin, 46, 393-400.

Górska, D., \& Cierpiałkowska, L. (2016). Mentalizacja jako stan i jako cecha - perspektywa strukturalno-procesualna [Mentalization as a state and as a trait - a structural and processual perspective]. In L. Cierpiałkowska \& D. Górska (Eds.), Mentalizacja z perspektywy rozwojowej i klinicznej [Mentalization from the developmental and clinical perspective] (pp. 13-42). Poznań: Wydawnictwo Naukowe UAM.

Górska, D., \& Marszał, M. (2014). Mentalization and theory of mind in borderline personality organization: exploring the differences between affective and cognitive aspects of social cognition in emotional pathology. Psychiatria Polska, 48, 503-513.

Ha, C., Sharp, C., Ensink, K., Fonagy, P., \& Cirino, P. (2013). The measurement of reflective function in adolescents with and without borderline traits. Journal of Adolescence, 36, 1215-1223.

Happé, F. G. E. (1994). An advanced test of theory of mind: Understanding of story characters' thoughts 
and feelings by able autistic, mentally handicapped, and normal children and adults. Journal of Autism and Developmental Disorders, 24, 129-154.

Harari, H., Shamay-Tsoory, S. G., Ravid, M., \& Levkovitz, Y. (2010). Double dissociation between cognitive and affective empathy in borderline personality disorder. Psychiatry Research, 175, 277-279.

Inoue, Y., Tonooka, Y., Yamada, K., \& Kanba, S. (2004). Deficiency of theory of mind in patients with remitted mood disorder. Journal of Affective Disorders, 82, 403-409.

James, R., \& Blair, R. (2007). Empathic dysfunction in psychopathic individuals. In T. Farrow \& P. Woodruff (Eds.), Empathy in Mental Illness (pp. 3-16). Cambridge University Press.

Kernberg, O. F. (2004). Borderline Personality Disorder and Borderline Personality Organization: Psychopathology and Psychotherapy. In J. J. Magnavita (Ed.), Handbook of Personality Disorders: Theory and Practice (pp. 92-119). Hoboken, NJ: John Wiley \& Sons, Inc.

Laranjo, J., Bernier, A., Meins, E., \& Carlson, S. M. (2014). The roles of maternal mind-mindedness and infant security of attachment in predicting preschoolers' understanding of visual perspective taking and false belief. Journal of Experimental Child Psychology, 125, 48-62.

Lecours, S., \& Bouchard, M.-A. (2011). Verbal elaboration of distinct affect categories and BPD symptoms. Psychology and Psychotherapy, 84, 26-41; discussion 98-110.

Levy, K. N., \& Blatt, S. J. (1999). Attachment theory and psychoanalysis: Further differentiation within insecure attachment patterns. Psychoanalytic Inquiry, 19, 541-575.

Levy, K. N., Meehan, K. B., Weber, M., Reynoso, J., \& Clarkin, J. F. (2005). Attachment and borderline personality disorder: implications for psychotherapy. Psychopathology, 38, 64-74.

Levy, K. N., Scala, J. W., Temes, C. M., \& Clouthier, T. L. (2015). An integrative attachment theory framework of personality disorders. In S. K. Huprich (Ed.), Personality disorders: Toward theoretical and empirical integration in diagnosis and assessment (pp. 315-343). Washington, DC: American Psychological Association.

Luyten, P., \& Fonagy, P. (2015). The neurobiology of mentalizing. Personality Disorders: Theory, Research, and Treatment, 6, 366-379.

Marszał, M. (2014). Specyficzne wewnętrzne modele operacyjne przywiązania osób z organizacją osobowości borderline [Relationship-specific attachment models in individuals with borderline personality organization]. Psychologia Rozwojowa, 19, 69-82.

Marszał, M. (2015). Mentalizacja w kontekście przywiqzania. Zdolność do rozumienia siebie $i$ innych u osób z osobowościa borderline [Mentalization in the context of attachment. The ability to understand self and others in people with borderline personality]. Warszawa: Difin.

Marszał, M. (2016). Metody pomiaru zdolności do mentalizacji [Methods of measuring the ability to mentalize]. In L. Cierpiałkowska \& D. Górska (Eds.), Mentalizacja z perspektywy rozwojowej $i$ klinicznej [Mentalization from the developmental and clinical perspective] (pp. 65-93). Poznań: Wydawnictwo Naukowe UAM.

Marszał, M., \& Jańczak, A. (2017). Emotion Dysregulation, Mentalization and Romantic Attachment in the Nonclinical Adolescent Female Sample. Current Psychology, 37, 1-11. doi: https://doi.org/ 10.1007/s12144-017-9573-0

Marszał, M., \& Kamza, A. (2016). Poznawcze źródła mentalizacji - koncepcja teorii umysłu [Cognitive roots of mentalization - the concept of the theory of mind]. In L. Cierpiałkowska \& D. Górska (Eds.), Mentalizacja z perspektywy rozwojowej i klinicznej [Mentalization from the developmental and clinical perspective] (pp. 65-93). Poznań: Wydawnictwo Naukowe UAM.

Meins, E., Fernyhough, C., Wainwright, R., Das Gupta, M., Fradley, E., \& Tuckey, M. (2002). Maternal mind-mindedness and attachment security as predictors of theory of mind understanding. Child Development, 73, 1715-1726.

Mikulincer, M., \& Shaver, P. R. (2003). The Attachment Behavioral System in Adulthood: Activation, Psychodynamics, and Interpersonal Processes. In M. P. Zanna (Ed.), Advances in experimental social psychology (Vol. 35, pp. 53-152). San Diego, CA: Elsevier Academic Press.

Müller, C., Kaufhold, J., Overbeck, G., \& Grabhorn, R. (2006). The importance of reflective functioning to the diagnosis of psychic structure. Psychology and Psychotherapy: Theory, Research and Practice, 79, 485-494.

Oldershaw, A., Treasure, J., Hambrook, D., Tchanturia, K., \& Schmidt, U. (2011). Is anorexia nervosa a version of autism spectrum disorders? European Eating Disorders Review, 19, 462-474.

Ontai, L. L., \& Thompson, R. A. (2008). Attachment, Parent-Child Discourse and Theory-of-Mind Development. Social Development, 17, 47-60.

Petersen, R., Brakoulias, V., \& Langdon, R. (2016). An experimental investigation of mentalization ability in borderline personality disorder. Comprehensive Psychiatry, 64, 12-21.

Preißler, S., Dziobek, I., Ritter, K., Heekeren, H. R., \& Roepke, S. (2010). Social Cognition in Borderline Personality Disorder: Evidence for Disturbed Recognition of the Emotions, Thoughts, and Intentions of others. Frontiers in Behavioral Neuroscience, 4, 182.

Richell, R. A., Mitchell, D. G. V., Newman, C., Leonard, A., Baron-Cohen, S., \& Blair, R. J. R. (2003). Theory of 
mind and psychopathy: can psychopathic individuals read the "language of the eyes"? Neuropsychologia, 41, 523-526.

Ritter, K., Dziobek, I., Preißler, S., Rüter, A., Vater, A., Fydrich, T., Lammers, C. H., Heekeren, H. R., \& Roepke, S. (2011). Lack of empathy in patients with narcissistic personality disorder. Psychiatry Research, 187, 241-247.

Sayin, A., Oral, N., Utku, C., Baysak, E., \& Candansayar, S. (2010). Theory of mind in obsessivecompulsive disorder: Comparison with healthy controls. European Psychiatry: The Journal of the Association of European Psychiatrists, 25, 116-122.

Schilling, L., Wingenfeld, K., Löwe, B., Moritz, S., Terfehr, K., Köther, U., \& Spitzer, C. (2012). Normal mind-reading capacity but higher response confidence in borderline personality disorder patients. Psychiatry and Clinical Neurosciences, 66, 322-327.

Scott, L. N., Levy, K. N., Adams, R. B., \& Stevenson, M. T. (2011). Mental state decoding abilities in young adults with borderline personality disorder traits. Personality Disorders, 2, 98-112.

Semerari, A., Carcione, A., Dimaggio, G., Nicoló, G., Pedone, R., \& Procacci, M. (2005). Metarepresentative functions in borderline personality disorder. Journal of Personality Disorders, 19, 690-710.

Semerari, A., Colle, L., Pellecchia, G., Buccione, I., Carcione, A., Dimaggio, G., Nicolò, G., Procacci, M., \& Pedone, R. (2014). Metacognitive dysfunctions in personality disorders: correlations with disorder severity and personality styles. Journal of Personality Disorders, 28, 751-766.

Semerari, A., Colle, L., Pellecchia, G., Carcione, A., Conti, L., Fiore, D., Moroni, F., Nicolò, G., Procacci, M., \& Pedone, R. (2015). Personality Disorders and Mindreading: Specific Impairments in Patients with Borderline Personality Disorder Compared to Other PDs. The Journal of Nervous and Mental Disease, 203, 626-631.

Sharp, C. (2014). The Social-Cognitive Basis of BPD: A Theory of Hypermentalizing. In C. Sharp \& J. L. Tackett (Eds.), Handbook of Borderline Personality Disorder in Children and Adolescents (pp. 211-225). New York, NY: Springer.

Sharp, C., \& Fonagy, P. (2008). The Parent's Capacity to Treat the Child as a Psychological Agent: Constructs, Measures and Implications for Developmental Psychopathology. Social Development, 17, 737-754.

Sharp, C., \& Kalpakci, A. (2015). Mentalization in borderline personality disorder: From bench to bedside. Personality Disorders: Theory, Research, and Treatment, 6, 347-355.

Sharp, C., Pane, H., Ha, C., Venta, A., Patel, A. B., Sturek, J., \& Fonagy, P. (2011). Theory of mind and emotion regulation difficulties in adolescents with borderline traits. Journal of the American Academy of Child and Adolescent Psychiatry, 50, 563-573.e1.
Shorey, H. S., \& Snyder, C. (2006). The role of adult attachment styles in psychopathology and psychotherapy outcomes. Review of General Psychology, 10, 1-20.

Stawicka, M., \& Górska, D. (2016). Mentalizacja w kontekście przywiązania [Mentalization in the context of attachment]. In L. Cierpiałkowska \& D. Górska (Eds.), Mentalizacja z perspektywy rozwojowej $i$ klinicznej [Mentalization from the developmental and clinical perspective] (pp. 42-65). Poznań: Wydawnictwo Naukowe UAM.

Taubner, S., White, L. O., Zimmermann, J., Fonagy, P., \& Nolte, T. (2013). Attachment-related mentalization moderates the relationship between psychopathic traits and proactive aggression in adolescence. Journal of Abnormal Child Psychology, 41, 929-938.

White, S., Hill, E., Happé, F., \& Frith, U. (2009). Revisiting the strange stories: revealing mentalizing impairments in autism. Child Development, 80, 1097-1117. 